\section{Arylation of Heterocycles via C-H Activation and Cross-Coupling with Aryl Chlorides}

Metal-Mediated Synthesis

Key words

palladium

arylation

electron-rich heterocycles

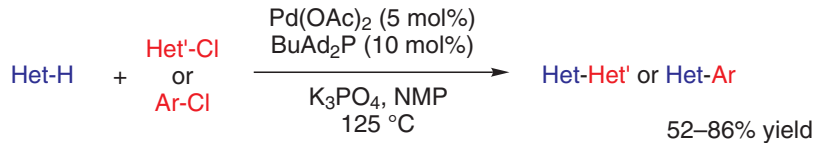

aryl chlorides

Het- $\mathrm{H}=$ thiophene, benzothiophene, 3,5-dimethylisoxazole, benzoxazole, benzothiazole, 2-isobutylthiazole,

2-pivaloylaminothiazole, 1-butylimidazole,

1-methyl-1,2,4-triazole, caffeine

Het'-H = 2-chloro-6-methoxypyridine, 2-chloropyridine

$\mathrm{Ar}-\mathrm{H}=$

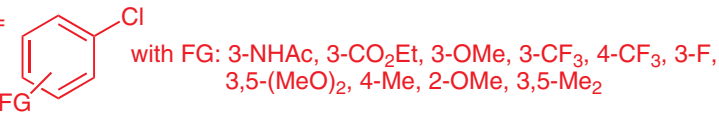

Selected examples:<smiles>Cc1cc(C)on1</smiles><smiles>Clc1cccc2ccccc12</smiles>

Pd(OAC) $(5 \mathrm{~mol} \%)$ $\operatorname{BuAd}_{2} \mathrm{P}(10 \mathrm{~mol} \%)$

$\mathrm{K}_{3} \mathrm{PO}_{4}, \mathrm{NMP}$ $125^{\circ} \mathrm{C}$<smiles>Cc1noc(C)c1-c1cccc2ccccc12</smiles><smiles>Cn1c(=O)c2c(ncn2C)n([O-])c1=O</smiles><smiles>COc1ccccc1Cl</smiles>
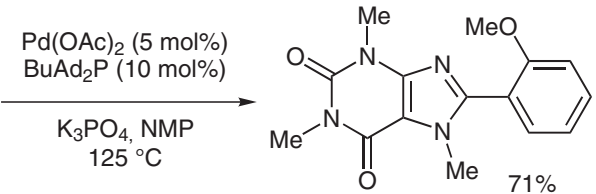

Significance: A new cheap and general method for the cross-coupling of heterocycles is presented in this article. A wide range of heterocycles was subjected to $\mathrm{Pd}$-catalyzed $\mathrm{C}-\mathrm{H}$ activation with subsequent cross-coupling to aryl and heteroaryl chlorides. This method was shown to be applicable to both electron-rich and electron-poor aryl chlorides furnishing good yields in almost all cases.
Comment: This new $\mathrm{C}-\mathrm{H}$ activation-cross-coupling sequence has a very high practical value for the syntheses of biologically active compounds. A number of heterocycles are shown to be directly functionalizable by $\mathrm{C}-\mathrm{H}$ activation. The possibility of their cross-coupling with the readily available aryl chlorides which are cheaper than their bromide or iodide equivalents is of considerable economic interest. 